\section{O TRABALHO EM COOPERATIVAS DE RECICLAGEM DE LIXO: ASPECTOS SOCIOAMBIENTAIS SEGUNDO A ÓTICA DOS COOPERADOS}

\author{
Work in Waste Recycling Cooperatives: Social and \\ Environmental Aspects According to the Optic of Members
}

\author{
El Trabajo de Reciclaje de Desechos en Cooperativas: \\ Aspectos Sociales y Ambientales de Acuerdo a la Optica De \\ sus Miembros
}

\section{Le Travaille dans les Coopératives de Recyclage des Déchet: Aspects Sociales et Environnementales Selon L'optique des Travailleurs}

\begin{abstract}
Resumo
Desde a revolução industrial, os resíduos se modificaram em quantidade e composição, tornando-se um dos grandes problemas socioambientais da atualidade. O consumo de produtos em embalagens descartáveis e a carência de áreas para deposição dos rejeitos têm na reciclagem uma importante alternativa para essa questão. A atividade de separação dos resíduos recicláveis possui grande relevância tanto socioeconômica quanto ambiental. O objetivo deste estudo descritivo tipo survey foi levantar o perfil e as concepções dos trabalhadores cooperativados de uma capital nordestina acerca de seu trabalho/profissão, dos riscos à saúde e do seu papel na preservação ambiental na comunidade onde trabalham. Participaram 26 separadores de resíduos recicláveis que atuam em duas cooperativas de Maceió. Os dados levantados através de formulário validado apontaram, através de análise quali-quantitativa, que os sujeitos percebem a valorização social do trabalho desenvolvido, que além de um meio de sobrevivência, é uma forma de fazer amigos e contribui para a sua inclusão social. Quanto à conscientização ambiental, $63 \%$ das respostas indicaram o estabelecimento da relação entre a atividade e a preservação do ambiente. Detectou-se, entretanto, que $69 \%$ dos sujeitos desconhecem o termo reciclagem. Quanto aos riscos à saúde, os cooperados reconhecem a falta de condições básicas e de infraestrutura nas cooperativas pesquisadas. Sugere-se o desenvolvimento de políticas públicas, programas de educação ambiental e saúde ocupacional que integre as dimensões do problema em suas interfaces e possa resgatar a dignidade desses trabalhadores.
\end{abstract}

Palavras-chave: catadores; uso de resíduos sólidos; percepção; atitude; inclusão social.

\section{Abstract}

Since industrial revolution, the waste has changed in quantity and composition, becoming one of the great social and environmental problems of today. The consumption of disposable packaging products and the lack of areas for waste disposal sees in recycling an important alternative for that issue. The recycled waste separation activity has both environmental and socio-economic importance. This survey-type descriptive study aims to raise profile and conceptions of cooperative workers from a brazilian northeastern capital concerning his job/profession, health risks and their role about environmental preservation into their working community. The participants included 26 recyclable waste workers that operate in two cooperatives in Maceio city. The data collected through validated form indicates by qualitative and quantitative analysis that the subjects understand the social value of their work, contributing to its social inclusion as a means of survival and a way to make friends. With regards to environmental awareness, $63 \%$ of responses indicated the establishment of the relationship between activity and environmental protection. It turned out, however,
Artigo Original
1) Enfermeira, Mestre em Saúde e Ambiente UNIT/SE.

2) Fonoaudióloga, Especialista em Saúde do Trabalhador, Mestre em Saúde e Ambiente.

3) Psicóloga, Doutora em Psicologia, Ciência e Profissão - PUCCampinas/SP. Universidade Tiradentes e Instituto de Tecnologia e Pesquisa.
Recebido em: 04/04/2012 Revisado em: 03/05/2013 Aceito em: 23/10/2013 
that $69 \%$ are unaware of the term recycling. As for health risks, the cooperative recognize the lack of basic conditions and infrastructure in the cooperatives. It is suggested the development of public policies, environmental education and occupational health programs integrating the dimensions of the problem in its interfaces and rescuing the dignity of these workers.

Keywords: solid waste segregators; solid waste use; perception; attitude; social inclusion.

\section{Resumen}

Desde la revolución industrial, los residuos cambian en cantidad y composición, convirtiéndose en uno de los principales problemas socio ambientales de hoy. El consumo de productos con envases desechables y la escasez de áreas para descartar residuos sólidos tienen en el reciclaje una importante alternativa para este asunto. La actividad de separación de desechos reciclables tiene gran importancia ambiental y socioeconómica. El objetivo de esta encuesta -con un estudio descriptivo-, es conocer el perfil y las percepciones de los trabajadores de cooperativas de la capital brasileña acerca de su trabajo y profesión, así como los riesgos para la salud y su papel en la preservación del medio ambiente en la comunidad donde trabajan. Participaron 26 personas clasificadoras de residuos reciclables de dos cooperativas de Maceió/Brasil. Los datos recogidos a través del formulario validado y el análisis cuali-cuantitativo demostraron que los sujetos perciben el reconocimiento social de su trabajo, contribuyendo a su inclusión social como medio de supervivencia y una manera de hacer amigos. Con respecto a la conciencia ambiental, 63\% de las respuestas indican el establecimiento de la relación entre la actividad y la preservación del medio ambiente. Sin embargo, se encontró que el 69\% desconoce el término reciclaje. Con respecto a los riesgos para la salud, los miembros de las cooperativas señalan la falta de condiciones básicas y de infraestructura en las mismas. Se propone entonces el desarrollo de políticas públicas, programas de educación ambiental y salud ocupacional mediante la integración de las dimensiones del problema en sus interfaces para que sea posible rescatar la dignidad de los trabajadores.

Palabras clave: clasificadores de residuos sólidos; uso de residuos sólidos; percepción; actitud; inclusión social.

\section{Résumé}

Depuis la révolution industrielle, les déchets ont changé en quantité et en composition, ce qui en fait un des principaux problèmes sociaux aujourd'hui. La consommation de produit jetable ainsi que le manque de zones de dépôt d'ordures trouvent dans le recyclage une alternative importante. L'activité de la séparation des déchets recyclés a une grande importance environnementale et socio-économique. L'objectif de ce type d'étude de sondage descriptive a été de relever le profil et les conceptions des travailleurs d'une coopérative d'une capitale du nord-est, de leur travail/profession, des risques pour la santé et du rôle dans la préservation de l'environnement dans la communauté où ils travaillent. Ont participé 26 séparateurs de déchet recyclable de deux coopératives de Maceió.Les données recueillies par le biais du formulaire validé par l'analyse a souligné quali-quantitative, que les sujets comprennent la reconnaissance sociale du travail accompli, qui en plus d'un moyen de survie, est un moyen de se faire des amis et contribue à leur insertion sociale. À l'égard de la sensibilisation à l'environnement, $63 \%$ des réponses indiquent l'établissement de la relation entre l'activité et la préservation de l'environnement. On a constaté cependant que $69 \%$ des sujets ne connaissent pas le terme recyclage. À l'égard des dangers pour la santé, les membres de la coopérative reconnaissent l'absence de conditions de base et dl'infrastructure.Il est suggéré l'élaboration de politiques publiques, des programmes de santé et éducation environnementale qui intègrent les dimensions du problème dans ses interfaces et donc redonnent de la dignité à ces travailleurs.

Mots-clés: segregators de déchets solides; utilisation des déchets solides; perception; attitude; inclusion sociale.

Com a grande expansão do consumo, observada a partir da Revolução Industrial, os resíduos se modificaram em quantidade e composição, tornando-se um dos grandes problemas sócio ambientais da atualidade, frente à falta de área para deposição dos rejeitos e seu alto potencial de contaminação para o ambiente (Siqueira, 2007).

Embora a produção de resíduos seja inerente à atividade humana, a relação entre um e outro é conflituosa. Pois, assim como os resíduos são depositados em locais mais afastados, as pessoas que trabalham com o lixo são discriminadas e tratadas como de terceira categoria (Portilho, 2006). Elas acompanham os resíduos, tirando deles o que ainda pode ser aproveitado. São muitos os esforços desses trabalhadores para vencerem o estigma social ainda forte, e para se identificarem como categoria profissional que desenvolvem uma função que exige certo conhecimento e experiência. O desejo do afastamento dos resíduos sólidos camufla o grande aspecto simbólico, que ocorre também entre esses trabalhadores, que vai além da dimensão física relacionada à saúde, doenças e contaminação (Velloso, 2004).

Os catadores de materiais recicláveis, que se inserem na categoria dos "inimpregáveis" e daqueles que sofrem os efeitos colaterais da modernidade, sobrevivem das sobras dos que estão incluídos na vida formal, reconhecidos como comunidade residual (Cunha, 2009). A desqualificação social dos catadores está relacionada também ao fato da catação se mostrar como uma fonte de garantir trabalho e renda e não como um movimento de consciência ambiental ou de uma escolha real e legítima pela atividade. Eles são excluídos econômica e politicamente em decorrência da pobreza e das restrições para acesso aos direitos garantidos por lei (Gesser \& Zenni, 2004). Há, também, uma banalização dos riscos inerentes ao trabalho com o lixo e o conhecimento que o trabalhador possui sobre o processo e necessidade de proteção não é suficiente para a adoção de ações preventivas (Cavalcante \& Franco, 2007).

A organização em cooperativas surge como tentativa 
de minimizar esse sentimento de exclusão. Nelas os trabalhadores se reúnem de forma a se tornarem donos de sua própria empresa. As cooperativas, entretanto, enfrentam problemas relacionados à falta de conhecimentos para gestão e dificuldades econômicas, levando-as a separar e enfardar o lixo reciclável e entregá-los para sucateiros, também reconhecidos como atravessadores, que possuem poder de barganha e acesso a indústrias e microempresas que processam essa matéria prima (Araújo, 2005; Kirchner, Saidelles \& Stumm, 2009; Magera, 2003; Medeiros \& Macedo, 2006).

A atividade na cooperativa normalmente está ligada à economia formal, de precária autonomia, considerando a ausência de garantia dos direitos aos trabalhadores autônomos, remuneração incerta e precária, o preconceito e a percepção de executarem um trabalho desvalorizado (Nascimento, 1995).

Segundo palavras de Fadini e Fadini, (2001, p. 17):

As cooperativas de catadores de lixo representam uma alternativa de saída do homem dos lixões e o resgate da sua condição de cidadão, com direitos a benefícios sociais, educação para os filhos, autonomia administrativa e possibilidade de ascensão social.

Para Zacarias e Bavaresco (2009), os determinantes da saúde (a alimentação, a moradia, o saneamento básico, o meio ambiente, o trabalho, a renda, a educação, o transporte, o lazer e o acesso aos bens e serviços essenciais, conforme Lei Federal $n^{\circ} 8.080$ de 19 de setembro de 1990) devem ser enfrentados em toda sua amplitude, pois o modo de produção, as condições de trabalho e o modo de vida constituem o patamar para se analisar o processo de saúde, adoecimento e mortes. Segundo Caixeta e Barbosa-Branco (2005), biossegurança é o termo utilizado para definir o conjunto de ações voltadas para a prevenção, minimização ou eliminação de riscos inerentes às atividades de pesquisa, produção e ensino, desenvolvimento tecnológico e prestação de sérvios, visando à saúde do homem, dos animais, a preservação do meio ambiente e a qualidade dos resultados. Segundo Neves, Cortez e Moreira (2006), a biossegurança é concebida como ação educativa, ao invés de reduzi-la a treino e introjeção de normas.

As atividades capazes de proporcionar dano, doença ou morte para os seres vivos são caracterizadas como atividades de risco. O risco ocupacional pode ser considerado uma ou mais condições no trabalho com potencial para causar danos. Esses danos podem ser entendidos como lesões a pessoas, danos a equipamentos ou estruturas, ou na redução da capacidade de desempenho de uma função pré-determinada (Lazzari \& Reis, 2011). Ferreira e Anjos (2001) consideram também como risco ocupacional a existência de riscos sociais, caracterizando-os pela falta de treinamento e de condições adequadas de trabalho. Para proteger os trabalhadores do contato com agentes infecciosos, tóxicos, corrosivos, calor excessivo, fogo e outros são utilizados os equipamentos de proteção individual $\left(\mathrm{EPI}^{1}\right)$, como luvas, máscaras, óculos de proteção, uniforme, avental impermeável e botas; e os equipamentos de proteção coletiva como exemplo: chuveiro de emergência e extintor de incêndio.

Outro aspecto relativo à atividade de separação de resíduos é o educacional, comprometido com os aspectos ambientais. Neste sentido, a educação ambiental pode ser considerada como um processo de conscientização política, institucional e comunitária da realidade ambiental, do homem e da sociedade. Deve analisar em conjunto com a comunidade, as melhores alternativas de proteção da natureza e do desenvolvimento socioeconômico do homem e da sociedade. Através da educação ambiental o ser humano é capaz de gerar mudanças significativas ao trilhar caminhos que levam a um mundo socialmente mais justo e ecologicamente sustentável. Os fatores objetivos e racionais da preservação devem estar aliados à sensibilidade humana a fim de despertar o interesse, o engajamento e a participação de indivíduos em assuntos relacionados a temas sócios ambientais (Stolz \& Vaz, 2009).

Diante do contexto apresentado e considerando a falta de insumos básicos, da infraestrutura inadequada das cooperativas, a exposição desses trabalhadores aos diferentes riscos ocupacionais como os sociais, psicológicos, biológicos, físicos dentre outros, na atividade de separação dos resíduos, o presente trabalho visa o levantamento da percepção dos cooperados quanto aos riscos do manuseio do lixo, o conhecimento de medidas de biossegurança ligadas à tarefa; o conhecimento das opiniões sobre o seu trabalho/ profissão, e a repercussão percebida na comunidade; bem como levantar os conceitos que possuem acerca da reciclagem e sua contribuição na preservação do ambiente.

\section{Método}

Trata-se de estudo de tipo survey de caráter quantiqualitativo.

\section{Local}

O estudo foi realizado no Estado de Alagoas, nas Cooperativas de Reciclagem de Resíduos COOPREL (A) e COOPLUM (B), ambas na cidade de Maceió.

\section{Participantes}

Participaram da pesquisa 26 sujeitos cooperados, distribuídos nas duas cooperativas de reciclagem de lixo

\footnotetext{
1 De acordo com a NR 6 - Equipamento de Proteção Individual EPI. Disponível em: http://www.mte.gov.br
} 
de Maceió-AL, sendo 17 da Cooperativa A e 9 da B, que eram compostas por 17 e 13 associados, respectivamente, dos quais quatro foram excluídos, por não atenderem o critério de inclusão de estarem desenvolvendo suas atividades continuamente por período mínimo de 04 meses, e aceitaram participar da pesquisa.

\section{Instrumento}

Utilizou-se um formulário para o levantamento dos dados sociodemográficos, do conhecimento dos cooperados acerca da segurança no trabalho os conceitos pessoais e percepção social sobre o trabalho realizado; além de opiniões, percepções e atitudes acerca da reciclagem. O instrumento passou por validação de conteúdo pelo método faced validity.

\section{Procedimentos}

Após visitas às cooperativas para explicar os objetivos da pesquisa e apoio das mesmas, os Termo de Consentimento Livre Esclarecido foi explicado de forma geral para os cooperados e lido e esclarecido novamente ao ser assinado individualmente em momento anterior à entrevista. Nesse momento foi realizado o preenchimento do formulário e colhidas outras informações através das verbalizações livres dos sujeitos acerca de suas rotinas e histórias. Os dados obtidos, como as características sócio demográficas e utilização de medidas de segurança foram analisados através de frequências absolutas e relativas. Os demais dados foram tratados pela Análise de Conteúdo (Bardin, 1977/2009) e os temas agrupados em seis categorias de respostas: opinião sobre o trabalho; percepção e atitudes da comunidade ante a tarefa de coleta dos resíduos recicláveis; mudanças na vida do sujeito após inserção na cooperativa; percepção da relação entre a atividade específica e a preservação ambiental; conceito de reciclagem e importância percebida da reciclagem para o meio ambiente.

\section{Considerações Éticas}

A pesquisa foi submetida e aprovada pelo Comitê de Ética em Pesquisa da Universidade Tiradentes, conforme Parecer Consubstanciado no 040609 de 23/06/2009. As entrevistas foram realizadas somente após a leitura e assinatura do Termo de Consentimento Livre Esclarecido. A identificação dos sujeitos foi preservada através de codificação, seguindo a Resolução n ${ }^{\circ} 196$ de 10 de outubro de 1996 do Conselho Nacional de Saúde.

\section{Resultados e Discussão}

\section{Caracterização Sócio Demográfica dos Sujeitos}

No grupo de cooperados pesquisados constatou-se que $54 \%$ são constituídos por homens e $46 \%$ por mulheres, na faixa etária de 18 a 45 anos, e foi observada a presença de um adolescente (Tabela 1). A distribuição por gênero evidencia a presença feminina, sob alegação que o trabalho na linha de triagem/separação exigiria menor esforço físico, e principalmente porque as mulheres são mais caprichosas, sendo possível aproveitar praticamente tudo que elas separam.

Segundo Porto et al. (2004), o fator idade revela que a população de catadores é formada basicamente por adultos jovens, embora ocorra uma grande elasticidade na faixa etária. Na atual conjectura econômica brasileira, a idade é um dos fatores que afetam predominantemente a forma de participação no mercado de trabalho formal, sendo mais favorável na admissão de jovens. Isso não ocorre nas cooperativas por não existir critérios para seleção para dos cooperados (Kirchner, Saidelles, \& Stumm, 2009).

Quanto à escolaridade, a maioria $(88 \%)$ estudou no ensino formal, e $12 \%$ declarou nunca ter frequentado escolas. O tempo de escolaridade médio dos sujeitos foi de três anos e meio. De um modo geral os sujeitos da pesquisa

Tabela 1

Caracterização dos separadores de resíduos recicláveis das cooperativas

\begin{tabular}{lcc}
\hline VARIÁVEIS & $f$ & $\%$ \\
SEXO & 14 & 54 \\
\hline Masculino & 12 & 46 \\
Feminino & $\mathbf{2 6}$ & $\mathbf{1 0 0}$ \\
\hline TOTAL & & \\
\hline ESCOLARIDADE & 3 & 12 \\
\hline Analfabeto & 23 & 88 \\
Fundamental Incompleto & $\mathbf{2 6}$ & $\mathbf{1 0 0}$ \\
\hline TOTAL & & \\
\hline IDADE & 01 & 04 \\
\hline$<18$ anos & 10 & 38 \\
$>18$ a 25 anos & 05 & 19 \\
$>35$ a 35 anos 45 anos & 06 & 23 \\
$>45$ anos & 04 & 15 \\
\hline TOTAL & $\mathbf{2 6}$ & $\mathbf{1 0 0}$ \\
\hline
\end{tabular}


seguem a ocupação familiar de catadores. Segundo Osava (2005), a discriminação é um fator determinante para a reduzida permanência dos filhos de catadores na escola devido a humilhações e preconceito sofridos. A baixa escolaridade foi observada também em estudos anteriores realizados por Silva (2002), Magera (2003), Velloso (2004), Martins (2007) e Bosi (2008) como um dos motivos que leva as pessoas à exclusão social.

A escolha dessa atividade pelos que estão no início da vida produtiva e aqueles que se aproximam do final da vida economicamente útil resultam da falta de oportunidade no mercado formal de trabalho, bastante competitivo e excludente e da facilidade de ingresso nas cooperativas, cuja dinâmica admissional é desprovida de burocracia, e tem por critérios a indicação feita por cooperado, na tentativa de reduzir a oscilação no número de componentes e contribuir para segurança do grupo. Por outro lado, com a adoção de práticas e valores coletivos o pertencimento social e a recuperação do sentido de coletividade poderiam ser favorecidos no sentido da conquista de uma qualificação social (Pizzio, 2009).

A maioria dos cooperados sobrevive com a renda mensal em torno de meio salário mínimo. Esses trabalhadores, mesmo inseridos no mercado de trabalho formal continuam excluídos, com renda que os mantém abaixo da linha de pobreza (Tabela 2). Medeiros e Macedo (2006) abordam essa dualidade, inclusão - exclusão, contextualizando que ao tempo em que se insere o separador de resíduos no mercado de trabalho, ele se torna excluído socialmente pelas condições precárias de trabalho e renda da atividade.

Quanto ao tempo de atividade nas cooperativas, 38\% dos pesquisados possuíam menos de um ano. A função de catador é considerada recente (Ferreira, 2005). Por outro lado, este dado confirma a crescente exclusão social nos dias atuais, agravada pela frequente movimentação dos associados, com abandono da atividade, especialmente em momentos de crise econômica. Por exemplo, a crise econômica mundial declinou o preço dos materiais em até $60 \%$ do valor praticado, segundo dados do Compromisso Empresarial Para Reciclagem (2009), motivado pela diminuição do crédito e da renda, que causou a queda no consumo e, consequentemente, na produção de lixo.

Os cooperados com mais de quatro anos na atividade encontram-se na faixa etária acima dos 40 anos. Para esses trabalhadores a atividade representa a condição de sobrevivência, pois acumulam uma vivência de exclusão, pobreza e catação no lixão.

A maioria dos associados (77\%) reside com até cinco pessoas, e em casas próprias, construídas com blocos de tijolos ou concreto, cedidos pela administração da cidade através de programas sociais. Constatou-se que mais de $90 \%$
Tabela 2

Caracterização das condições socioeconômicas dos cooperados

\begin{tabular}{lll}
\hline VARIÁVEIS & $f$ & $\%$ \\
RENDA FAMILIAR & 19 & 73 \\
\hline Até $1 / 2$ salário mínimo & 07 & 27 \\
> de $1 / 2$ salário mínimo & $\mathbf{2 6}$ & $\mathbf{1 0 0}$ \\
\hline TOTAL & & \\
\hline TEMPO DE ATIVIDADE & 10 & 38 \\
\hline De 04 meses a 01 ano & 02 & 08 \\
+ 01 a 02 anos & 01 & 04 \\
+ 02 a 03 anos & 05 & 19 \\
+ 03 a 04 anos & 08 & 31 \\
+ de 4 anos & $\mathbf{2 6}$ & $\mathbf{1 0 0}$ \\
\hline TOTAL & & \\
\hline TIPO DE RESIDÊNCIA & 24 & 92 \\
\hline Uni familiar & 02 & 08 \\
\hline Multifamiliar & $\mathbf{2 6}$ & $\mathbf{1 0 0}$ \\
\hline TOTAL & &
\end{tabular}

das residências não são atendidas pelo sistema de coleta municipal, de forma sistemática. Essa situação promove a deposição inadequada dos resíduos no ambiente próximo às moradias. Também as cooperativas convivem com essa realidade e termina por acumular rejeito nos arredores dos galpões por não haver programação para coleta regular. O rejeito é toda sobra de resíduos resultante da triagem ou separação dos recicláveis.

\section{Conhecimentos dos Cooperados Acerca da Segurança no Trabalho}

Foi identificado no grupo pesquisado que $65,4 \%$ dos entrevistados possuíam conhecimento sobre prevenção de acidentes no trabalho, sendo a forma mais frequentemente relatada $(57 \%)$ através de programas sobre meio ambiente exibidos pela televisão, que segundo eles explicavam de forma clara e em curto período de tempo, como lidar com os resíduos em cooperativas e na coleta urbana. Através da observação in loco, pode-se constatar também o uso habitual do rádio durante os turnos de trabalho. Esse veículo é responsável pelo conhecimento sobre biossegurança para $13 \%$ dos pesquisados, se mais explorado para propagação de informações educativas aos trabalhadores, funcionaria também como uma importante estratégia de educação ambiental. A Figura 1 detalha as formas de obtenção de informações sobre prevenção de acidentes no trabalho. 
Os cooperados referiram a inexistência de treinamento formal anterior sobre a prevenção de acidentes e auto cuidado no trabalho, as orientações são repassadas no grupo, quando da ocorrência de acidentes, como alerta para evitar novos casos. As respostas obtidas indicam o distanciamento dos órgãos sanitários e fiscalizadores das atividades desenvolvidas nos galpões de reciclagem. O planejamento e desenvolvimento de ações educativas junto aos agentes comunitários podem representar um passo para melhoria da atuação desses profissionais frente aos separadores de resíduos.

Dentre os cooperados, $61,5 \%$ reconheceram no uso de luvas de borracha e botas as principais medidas de biossegurança, pois consideraram frequentes os riscos de acidentes no trabalho realizado (ver Figura 2). O uso de uniforme foi observado em $45 \%$ dos pesquisados, e de botas em $10 \%$. Observou-se a improvisação de luvas com sacos plásticos recolhidos dos resíduos. Esse fato pode ter sido influenciado pela presença de pesquisador no campo.

Para Cavalcante e Franco (2007), o manuseio dos resíduos, principalmente pelos separadores, exige o conhecimento dos riscos de doenças, contaminação e dos Equipamentos de Proteção Individuais (EPIs). Conforme a Norma Regulamentadora - NR 6 do Ministério do Trabalho, EPI é todo e qualquer dispositivo ou produto de uso individual utilizado pelo trabalhador, destinado à proteção de riscos suscetíveis de ameaçar a segurança e a saúde no trabalho. Para quem manuseia os resíduos destacam-se as

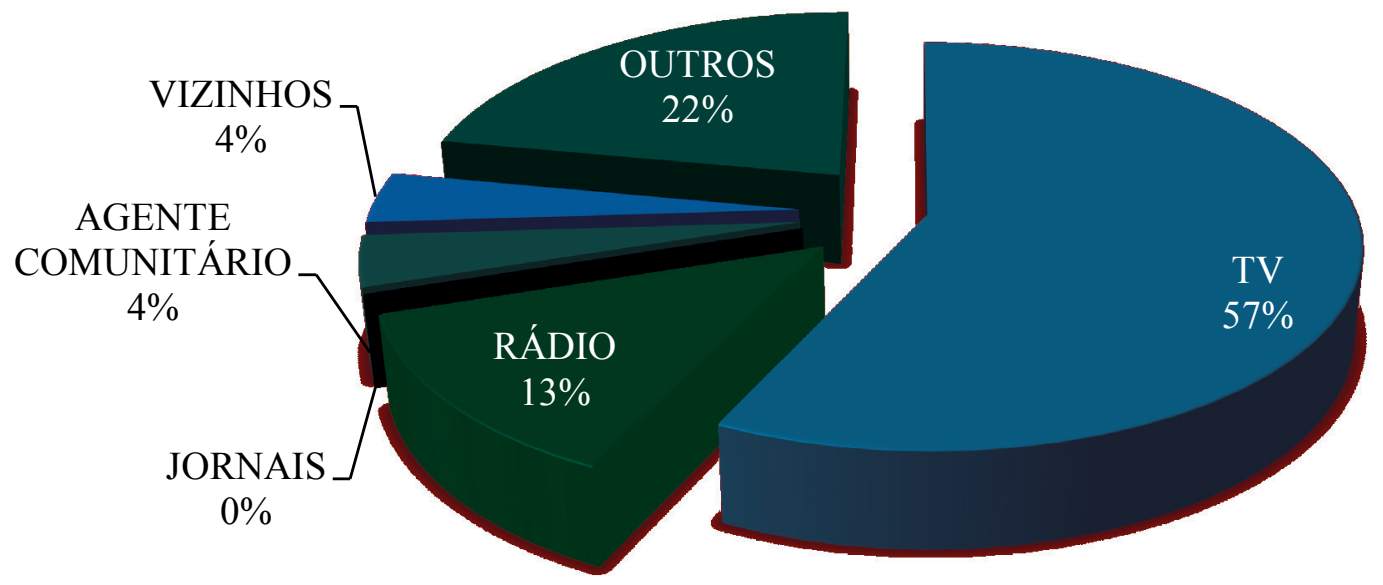

Figura 1. Formas de obtenção de informações sobre prevenção de acidentes no trabalho

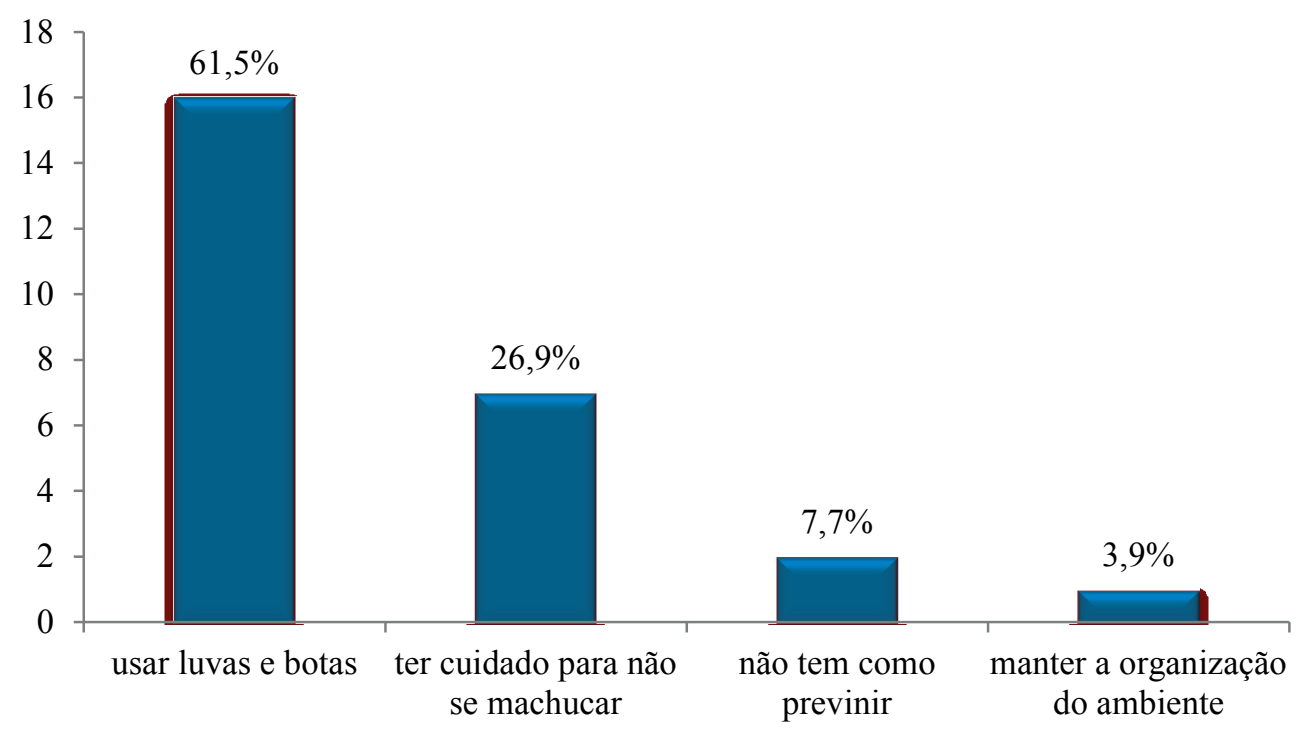

Figura 2. Medidas de biossegurança tomadas pelos cooperados 
máscaras faciais de tecido, óculos de segurança, aventais de plástico, botas e luvas de borracha. Zacarias e Bavaresco (2009) corroboram afirmando que perigoso ou não, o sentimento revelado pelos trabalhadores de resíduos é que é preciso continuar trabalhando, seja como for, com ou sem proteção. A importância de se proteger é sabida por todos, mas não está inserido no dia a dia de trabalho, provavelmente pela precariedade que cerca dialeticamente esta atividade e a própria condição social dos mesmos.

Apenas 19\% dos entrevistados souberam informar sobre seu estado vacinal. Foi observada certa insegurança ao confirmar as vacinas que tomaram: antitetânica, BCG, anti-hepatite, gripe e rubéola. Provavelmente ações de planejamento e o desenvolvimento de ações educativas, junto aos agentes comunitários poderão representar um passo importante para melhoria da atuação desses profissionais frente aos separadores de resíduos sólidos, conforme exemplifica a fala abaixo:

Aqui não vem o pessoal da saúde, a gente se vacina nas campanhas. O que a gente precisa mesmo é de vacina para leptospirose, por causa dos ratos, que são muitos. (Sujeito 21)

Lazarri e Reis (2011) ressalta a importância de treinamento dos trabalhadores, da conscientização da população para o descarte correto dos resíduos domiciliares, e da fiscalização por parte do setor de saúde do trabalhador e do ambiente para análise das condições de trabalho e minimização dos riscos.

$\mathrm{O}$ grupo estudado considerou como os materiais mais importantes para reciclagem pelo valor de comercialização os plásticos $51 \%$, metais $35 \%$ e papéis $10 \%$. Observada a confusão dos cooperados sobre os itens mais rentáveis, os mais facilmente encontrados e os prejudiciais ao ambiente. Das respostas obtidas 4\% expressaram o desconhecimento dos sujeitos sobre os preços dos recicláveis, considerandoos de igual importância comercial.

Todo material é importante porque a gente vende, mas o alumínio é o mais caro. (Sujeito 24)

Estes trabalhadores atuam na ponta da cadeia produtiva onde circula o lixo, porém esta colocação se reduz a um vínculo informal, sem acesso à remuneração ou a qualquer outro direito trabalhista. Para Medeiros e Macedo (2006), o trabalho autônomo dos catadores (ou autoemprego) não deixa de ser uma venda da sua força de trabalho à indústria da reciclagem, sem, contudo, estabelecer um contrato de trabalho e ter acesso a direitos trabalhistas. Já, para a indústria, a utilização dos resíduos sólidos como matéria prima, segundo Gonçalves (2005), reduz os gastos com o processo de produção com ganho de energia e redução na quantidade de matéria prima natural utilizada, além de reduzir a poluição ambiental. Assim, além do ganho econômico, o empresariado do setor é motivado pelo impacto na imagem da empresa como "ecorresponsável", pelo seu "compromisso ambiental" e seu desenvolvimento "autossustentável”.

\section{Conhecimento e Percepções dos Cooperados Acerca da Atividade e da Repercussão Social da Mesma}

Em relação ao trabalho realizado $56 \%$ das respostas apontaram para a valoração da atividade, como exemplificado a seguir, enquanto $35 \%$ referiram uma relação de afetividade com a mesma, o que demonstrou ser uma forma mais leve de enfrentar o cotidiano da separação dos materiais, além de representar uma oportunidade para ampliar o círculo social (Ver Tabela 3).

É um trabalho muito importante. Ele é a minha única fonte de salário. Melhor seria se fosse de carteira assinada. (Sujeito 01)

É um trabalho muito importante, porque beneficia muitas pessoas, e evita o ócio. Sinto orgulho de trabalhar na cooperativa, é melhor do que no lixão. (Sujeito 09)

Os discursos acima revelam o quanto é valorizado o modo de se sentir útil, de garantir a sobrevivência com trabalho próprio e dignidade. Porto et al. (2004), ressaltam que o desemprego representa o motivo mais marcante para uma ocupação no lixo. Outros autores como Fadini e Fadini (2001); Kirchner, Saidelles e Stumm (2009), abordam a questão de negação da realidade, mas através da separação dos resíduos, várias pessoas foram incluídas nesta atividade produtiva, o que culminou com a geração de renda, e de alguma forma para os cooperados e seus familiares modificou o significado dos resíduos, exercendo o papel importante na sua sobrevivência.

A percepção que os recicladores possuem sobre as atitudes da comunidade frente à coleta dos resíduos recicláveis (Ver Tabela 3) é de que a atividade é valorizada pela comunidade de forma positiva na maioria das respostas (64\%), tal como ilustra as falas a seguir:

As pessoas gostam do trabalho que a gente faz, porque limpa as ruas onde moram e livra os esgotos, então tá ajudando a natureza e isso é certo". (Sujeito 10)

Kirchner, Saidelles e Stumm (2009) corroboram 
afirmando que os catadores estão percebendo sua importância como categoria profissional, pois estão construindo uma nova história e definindo uma área de atuação, e que assim passam a acreditar na grande importância da atividade que realizam para o meio ambiente e a sociedade.

Somente $13 \%$ referiram atitudes de cooperação e curiosidade dos moradores dos bairros atendidos pela coleta seletiva para com o trabalho desenvolvido, o que também suscita a necessidade de políticas mais assertivas voltadas à educação ambiental (Ver Tabela 3).

Muitas pessoas ajudam separando o lixo, e algumas até traz prá cooperativa. Outras pessoas junta o material e reclama quando nós demora para recolher. Acho que é porque acham importante esse trabalho. (Sujeito 06)

São também negativamente considerados, conforme exemplifica o relato:

Falta consideração com os recicladores, e falta amor em quem separa o lixo nas casas, porque vem tudo misturado na coleta seletiva. Não é um trabalho bem visto. A gente favorece a todo mundo, mas não tem valorização. (Sujeito 15)

Das respostas obtidas, 23\% referiram desconhecer como o trabalho desenvolvido era visto pela sociedade (Ver Tabela 3). Os cooperados, de modo geral realizam a triagem dos materiais recicláveis, e só alguns participam na coleta seletiva. Estes resultados suscitam a necessidade de ações voltadas à educação ambiental informal, que atinja cada vez mais pessoas e dessa forma possibilite em médio e longo prazo, a mudança de atitude da sociedade quanto à preservação ambiental e a inclusão social destes trabalhadores.

Independentemente de juízos valorativos, reconhecimento ou cooperação, Medeiros e Macedo (2006) salientam que o trabalho com resíduos sólidos possui características que abarcam aspectos positivos e negativos, e por isso a relação dos pesquisados com os resíduos é ambígua, gera preocupação e sofrimento, refletindo a dialética inclusão/exclusão, saúde/doença, orgulho/ humilhação. Também, concorda-se com os referidos autores quando afirmam que não há como ignorar que as condições em que esses trabalhadores desenvolvem suas atividades são extremamente precárias. São inúmeros os riscos à saúde, eles são desprovidos de garantias trabalhistas que os ampare, são mal remunerados, vítimas de preconceitos e pouco reconhecidos pela comunidade. Sob esse prisma, o sofrimento no trabalho ocorreria também pela falta de reconhecimento (Bendassolli, 2011) enfatizado pelas condições de trabalho desta população.

Conforme se pode verificar na Tabela 3, os cooperados referiram que após a inserção nas cooperativas, as principais mudanças foram na inclusão social (37\%) e na condição de subsistência (34\%), como exemplifica a fala que segue:

Muita coisa mudou para melhor. Já fiquei sete meses sem emprego. Com esse trabalho ganho meu dinheiro, é pouquinho porque rende pouco. Aqui fiz amizades e a gente é como uma família. (Sujeito 01)

Tabela 3

Conhecimento e Percepção dos cooperados sobre as atividades desenvolvidas

\begin{tabular}{|c|c|c|c|}
\hline CATEGORIAS DE ANÁLISE & TEMAS & $f^{*}$ & $\%$ \\
\hline \multirow{4}{*}{ 1. OPINIÃO SOBRE O TRABALHO } & Valoração da atividade & 36 & 56 \\
\hline & Relação de afetividade & 23 & 35 \\
\hline & Respostas descritivas & 06 & 09 \\
\hline & Total & 35 & 100 \\
\hline \multirow{4}{*}{$\begin{array}{l}\text { 2. PERCEPÇÃO E ATITUDES DA COMUNIDADE ANTE A TAREFA DE } \\
\text { COLETA DOS RESÍDUOS RECICLÁVEIS }\end{array}$} & Juízos valorativos positivos & 33 & 64 \\
\hline & Desconhecimento & 12 & 23 \\
\hline & Cooperação e curiosidade & 07 & 13 \\
\hline & Total & 52 & 100 \\
\hline \multirow{4}{*}{$\begin{array}{l}\text { 3. MUDANÇAS NA VIDA DO COOPERADO APÓS INSERÇÃO NA } \\
\text { COOPERATIVA }\end{array}$} & Inclusão social & 21 & 37 \\
\hline & Condições de sobrevivência & 20 & 34 \\
\hline & Pouco ou nenhuma mudança & 17 & 29 \\
\hline & Total & 58 & 100 \\
\hline
\end{tabular}

Nota. “*” As respostas são cumulativas levantadas pela análise de conteúdo (Bardin, 1977/2009) e não correspondem ao tamanho da amostra. 
A coleta seletiva e a separação dos resíduos não representam que eles estão sendo autônomos no seu processo de sobrevivência, mas que buscaram uma alternativa porque não conseguiram se incluir nos padrões estabelecidos pelo sistema capitalista. Não se percebe ainda uma consciência ambiental, eles assimilam melhor o conceito de reutilizar, de reaproveitar, por ter como pano de fundo uma possibilidade para conquistarem os bens de consumo, através da renda gerada pela atividade. Assim, esse trabalho além de melhorar o meio ambiente, pode satisfazer as necessidades desses separadores, pois precisam, como qualquer pessoa, de dinheiro para alimentação, vestuário, moradia e lazer. Por outro lado a atividade envolve este ator social de tal maneira que o mesmo sente-se bem realizando este fazer (Stolz \& Vaz, 2009).

A percepção dos cooperados acerca da relação entre a atividade e a preservação ambiental foi relacionada, na maioria das falas, à coleta seletiva e à redução do impacto ambiental (Ver Tabela 4). Quanto ao conceito de reciclagem vale ressaltar o desconhecimento do termo por $39 \%$ dos sujeitos. Por outro lado, a importância da reciclagem para o ambiente aparece em $37 \%$ das falas que a consideraram um fator de proteção do meio ambiente e $10 \%$, também como uma forma de inclusão social, como exemplificam as falas:
Sei não o que é não [reciclagem], aqui eu coleto material, separo e vendo. Outros separa, prensa e vende. (Sujeito11) Vale muito, é um trabalho importante para a natureza. Retira o lixo das ruas, não prejudica os esgotos e evita as enchentes. (Sujeito 16)

... importante porque protege a natureza, diminui a poluição, ajuda a limpar a cidade e transforma os materiais. (Sujeito 02)

Os resultados dessa pesquisa corroboram os achados de Kirchner, Saidelles e Stumm (2009), ao apontarem que, para além da questão financeira, os cooperados consideram importante a afirmação referente à sua contribuição com o ambiente. Eles despontam como atores indispensáveis ao retorno do material para a indústria de reciclagem, como matéria prima para novos produtos, com economia dos recursos naturais e energia, além da inserção social através de ocupação valorizada e subsistência mais digna.

\section{Considerações Finais}

Os dados mostraram que a maioria dos cooperados é do sexo masculino, na faixa etária entre 18 e 45 anos,

Tabela 4

Conhecimento e Percepção dos cooperados sobre a relação da atividade com o meio ambiente

\begin{tabular}{|c|c|c|c|}
\hline CATEGORIAS DE ANÁLISE & TEMAS & $f^{*}$ & $\%$ \\
\hline \multirow{3}{*}{$\begin{array}{l}\text { 1. PERCEPÇÃO DA RELAÇÃO ENTRE A ATIVIDADE ESPECÍFICA E A } \\
\text { PRESERVAÇÃO AMBIENTAL }\end{array}$} & $\begin{array}{l}\text { Estabelecimento de relação } \\
\text { entre a atividade e a preservação } \\
\text { ambiental }\end{array}$ & 33 & 73 \\
\hline & $\begin{array}{l}\text { Não estabelece relação entre } \\
\text { a atividade e a preservação } \\
\text { ambiental }\end{array}$ & 12 & 27 \\
\hline & Total & 45 & 100 \\
\hline \multirow{4}{*}{ 2. CONCEITO DE RECICLAGEM } & Não sabe conceituar & 16 & 39 \\
\hline & Transformação do lixo & 13 & 31 \\
\hline & $\begin{array}{l}\text { Respostas descritivas que não } \\
\text { atingem um conceito }\end{array}$ & 12 & 03 \\
\hline & Total & 41 & 100 \\
\hline \multirow{5}{*}{ 3. IMPORTÂNCIA DA RECICLAGEM PARA O MEIO AMBIENTE } & Proteção do ambiente & 14 & 37 \\
\hline & $\begin{array}{l}\text { Não estabelece relação entre } \\
\text { a reciclagem e a preservação } \\
\text { ambiental }\end{array}$ & 11 & 29 \\
\hline & $\begin{array}{l}\text { Complemento da limpeza } \\
\text { urbana }\end{array}$ & 09 & 24 \\
\hline & Inclusão social & 04 & 10 \\
\hline & Total & 38 & 100 \\
\hline
\end{tabular}

Nota. “*” As respostas são cumulativas levantadas pela análise de conteúdo (Bardin, 1977/2009) e não correspondem ao tamanho da amostra. 
com ensino fundamental incompleto, com atividade nas cooperativas entre 2 e 5 anos. $77 \%$ moram em residência uni familiar própria, construída em bloco, com até cinco pessoas, e não desfrutam de sistema de coleta regular dos resíduos.

A renda mensal de $73 \%$ dos separadores de resíduos cooperados é menor de um salário mínimo, eles consideram o valor insuficiente para sustentar a família, mas é através do trabalho que eles se sentem inseridos socialmente. Apenas $27 \%$ possuem outra fonte e rendimento. Para os cooperados, os conceitos de reaproveitar ou reutilizar estão atrelados mais fortemente à geração de renda.

As medidas de biossegurança são conhecidas por $61,5 \%$ do grupo estudado, que tomaram conhecimento por programas veiculados pela televisão, e elegem as luvas e botas de borracha como os equipamentos de proteção individual mais importantes, embora não tenham assegurada a disponibilização dos mesmos para o uso.

Mesmo sem muita clareza do benefício ambiental proporcionado pela coleta seletiva e separação dos resíduos, os cooperados valorizam a atividade realizada e desenvolvem uma relação de afetividade com esse trabalho. Eles detêm reduzida visibilidade dos beneficiados pela ação, o que concorre para a baixa autoestima do grupo estudado.

Os objetivos do estudo foram alcançados, possibilitando apreender as percepções, conceitos e opiniões dos cooperados sobre o trabalho que realizam e sua repercussão na saúde, na sociedade e no ambiente.

Longe do fazer consciente, os cooperados seguem contribuindo para o processo de reciclagem, mesmo desconhecendo a importância do próprio papel na economia de energia e a na redução do uso de recurso natural virgem, ao possibilitar o retorno dos resíduos à indústria de reciclagem. E, nesse contexto, a educação ambiental é um fator determinante a formação de cidadãos ambientalmente conscientes.

Os resultados dessa pesquisa devem ser considerados para ampliar discussões, mover ações de gestores públicos visando melhorar as condições de trabalho nas cooperativas, tornando-as estruturas organizacionais capazes de possibilitar a inclusão justa, minimizando riscos à saúde, e ampliando os benefícios da educação ambiental. Entendese que pesquisas acerca do tema precisam ser realizadas em municípios que possuam ou não cooperativas de reciclagem, para entendermos com profundidade as percepções e atitudes da população em geral acerca da ocupação de catador de resíduos recicláveis e os aspectos subjetivos relacionados à mesma.

\section{Agradecimentos}

Aos cooperados, pela participação na pesquisa e a
Superintendência de Limpeza Urbana de Maceió - SLUM, pela permissão do acesso na COOPLUM.

\section{Referências}

Araújo, L. P. (2005). Os catadores de lixo e o processo de emancipacão. Ciência \& Saúde Coletiva, 10(1), 49-61.

Bardin, L. (2009). Análise de conteúdo (L. A. Neto, \& A. Pinheiro, Trad.). Lisboa: Persona/Edições 70. (Original publicado em 1977)

Bendassolli, P. F. (2011). Mal-estar no trabalho: Do sofrimento ao poder de agir. Revista Mal-estar e Subjetividade, 11(1), 65-99.

Bosi, A. P. (2008). A organização capitalista do trabalho "informal": O caso dos catadores de recicláveis. Revista Brasileira de Ciências Sociais, 23(67), 101-116.

Caixeta, R. B., \& Barbosa-Branco, A. (2005). Acidente de trabalho, com material biológico, em profissionais de saúde e hospitais públicos do Distrito Federal, Brasil, 2002/2003. Cadernos de Saúde Pública, 21(3), 737746.

Cavalcante, S., \& Franco, M. F. A. (2007). Profissão perigo: Percepção de risco à saúde entre os catadores do lixão do Jangurussu. Revista Mal-estar e Subjetividade, 6(1), 211-231.

Compromisso empresarial para reciclagem. (2009). Recuperado de $h t t p / /: w w w . c e m p r e . o r g . b r$

Cunha, M. R. R. L. (2009). Riscos e consumo: A construção da identidade a partir do lixo (Dissertação de mestrado não publicada). Universidade Federal de Goiás, Goiania.

Fadini, O. S., \& Fadini, A. A. B. (2001). Lixo: Desafios e compromissos. Cadernos Temáticos de Química Nova na Escola, 1, 9-18.

Ferreira, J. A., \& Anjos, L. A. (2001). Aspectos de saúde coletiva e ocupacional associados à gestão dos resíduos sólidos municipais. Cadernos de Saúde Pública, 17(3), 689-696.

Ferreira, S. L. (2005). Os "catadores do lixo" na construção de uma nova cultura: a de separar o lixo e da consciência ambiental. Revista Urutágua - Revista Acadêmica Multidisciplinar. Recuperado de www. uem.br/urutagua/007/07ferreira.htm

Gesser, M., \& Zeni, A. L. B. (2004). A construção de um programa de educação ambiental na comunidade: Interdisciplinaridade, subjetividade e cidadania. Anais do Congresso Brasileiro de Extensão Universitária, 


\section{Belo Horizonte, 1-6.}

Gonçalves, R. S. (2005). Catadores de materiais recicláveis: Trabalhadores fundamentais na cadeia de reciclagem do país. Revista Serviço Social \& Sociedade, 82(65), 87-109.

Kirchner, R. M., Saidelles, A. P. F. \& Stumm, E. M. F. (2009). Percepção e perfil dos catadores de materiais recicláveis de uma cidade de RS. Revista Brasileira de Gestão e Desenvolvimento Regional, 5(3), 221-232.

Lazzari, M. A., \& Reis, C. B. (2011). Os coletadores de lixo urbano do município de Dourados e sua percepção sobre os riscos biológicos em seu processo de trabalho. Revista Ciência e Saúde Coletiva, 16(8), 3437-3442.

Magera, M. (2003). Os empresários do lixo: Um paradoxo da modernidade. Campinas, SP: Átomo.

Martins, A. C. (2007). A Busca da proteção ao trabalho dos catadores de lixo recicláveis: Análise da experiência do Instituto do Lixo e Cidadania em Curitiba, PR (Dissertação de mestrado não publicada). Universidade Federal de Ponta Grossa, Ponta Grossa, PR.

Medeiros, L. F. R., \& Macedo, K. B. (2006). Catador de material reciclável: Uma profissão para além da sobrevivência? Psicologia \& Sociedade, 18(2), 62-71.

Ministério do Trabalho e Emprego. Norma Regulamentadora $\mathrm{n}^{\circ} 6$. Recuperado de http://www.mte.gov.br

Nascimento, E. P. (1995). Modernidade ética: Um desafio para vencer a lógica perversa da nova exclusão. In Proposta (n 65, pp. 24-28). Rio de Janeiro: Editora FASE.

Neves, T. P., Cortez, E. A., \& Moreira, C. O. F. (2006). Biossegurança como ação educativa: Contribuições à saúde do trabalhador. Cogitare Enfermagem, 1(11), 5054.

Osava, M. (2005). Meio ambiente e infertilidade. In Terramerica e cidadania. Edição 268 de 29/08/2005. Disponivel em: http.www. envolverde.com.br/ ambiente/terramerica-brasil. Recuperado em 10 outubro, 2009.

Pizzio, A. (2009). Desqualificação e qualificação social: uma análise teórico conceitual. Revista Mal-estar e Subjetividade, 9(1), 209-232.

Portilho, F. (2006). Representações sociais de profissionais do lixo: Para além de estigmas, repulsas e tabus. Saúde e Direitos Humanos, 1, 135-147.

Porto, M. F. S., Juncá, D. C. M., Gonçalves, R. S., \& Filhote, M. J. F. (2004). Lixo, trabalho e saúde: um estudo de caso com catadores em um aterro metropolitano no Rio de Janeiro. Cadernos de Saúde Pública, 20(6), 15031514.

Silva, A. C. (2002). Criteria for definition of environmental contamination indicators related to solid waste from health care facilities: A proposal for evaluation. Cadernos de Saúde Pública, 18(5), 1401-1409.

Siqueira, M. M. (2007). Resíduos Urbanos e os impactos na Saúde Coletiva do Município de São José do Rio Preto. Dissertação de Mestrado, FAMERP/SP, São Paulo, 2007.

Stolz, P. V. \& Vaz, M. R. C. (2009). Compreensão dos separadores de resíduos acerca do seu trabalho com o meio ambiente. Revista Eletrônica do Mestrado em Educação Ambiental, 22, 234-246. Disponivel em:http://www.seer.furg.br/remea/issue/archive. Recuperado em 10 outubro, 2009.

Velloso, M. P. (2004). Os catadores de materiais recicláveis e os resíduos sólidos. In VIII Congresso Luso-AfroBrasileiro de Ciências Sociais, Coimbra. Disponível em: http://www.ces.uc.pt/lab2004/inscricao/pdfs/ painel33/MartaVelloso.pdf. Recuperado em 10 outubro, 2009.

Zacarias, I. R., \& Bavaresco, C. S. (2009). Conhecendo a realidade dos catadores de materiais recicláveis da Vila Dique: visões sobre os processos de saúde e doença. Revista Textos \& Contextos, 8(2), 293-305

\section{Endereço para correspondência:}

Maria Rejane Calheiros da Virgem

E-mail: rejanecalheiros@yahoo.com.br 